\title{
Hydrothermal fields in the Mid-Atlantic Ridge: Setting and prospects for further discoveries
}

\author{
A. O. Mazarovich and S. Yu. Sokolov \\ Laboratory of Geomorphology and Ocean Floor Tectonics, Geological Institute, Russian Academy of \\ Sciences (GIN RAS)
}

\begin{abstract}
Analyzed is the setting of active and inactive hydrothermal fields and sulfide occurrences on the Mid-Atlantic Ridge between $65^{\circ} \mathrm{N}$ and $65^{\circ} \mathrm{S}$. Multifaceted interpretation of data has enabled a prediction of how sulfide mineralization is distributed in the Atlantic Ocean.
\end{abstract}

\section{Introduction}

Analyzing the InterRidge database [Hannington, 2001] shows that, by now, 97 active hydrothermal fields have been discovered in all the earth's oceans, including seas. Of the entire population, 15 occurrences fall in the Atlantic basin, 72 in the Pacific, and the rest in the Indian and Arctic oceans. This study is focused on the Atlantic Ocean alone, between Iceland on the north and the Bouvet triple junction (TJ) region on the south.

Several years ago, Mazarovich and Sokolov [1998] noted that on the Mid-Atlantic Ridge (MAR), hydrothermal fields become localized to rift zones with low to zero seismicity (for samples of $\mathrm{M} 4+$ events). In addition, these regions have been shown to contain discontinuities. Our analysis has covered the span between ca. $14^{\circ} \mathrm{N}$ and $30^{\circ} \mathrm{N}$. Based on these two criteria, hydrothermal mineral occurrences may be expected to exist south of $7^{\circ} \mathrm{N}$ in the Atlantic Ocean.

There, in the summer of 2000, cruise 22 of the $\mathrm{R} / \mathrm{V}$ Akademik Nikolai Strakhov (Geological Institute RAS) was conducted [Peyve et al., 2000], resulting in the detection of rocks that show hydrothermal alterations and sulfide mineralization. These new data have provided the basis for predicting sulfide mineralization for this area as well [Mazarovich et al., 2001]. Based on the prediction just mentioned and on the results of the SIMRAD EM-12 multibeam echo sounder bathymetric survey performed by the R/V Akademik Nikolai Strakhov, this area was re-explored

Copyright 2002 by the Russian Journal of Earth Sciences.

Paper number TJE02104.

ISSN: $1681-1208$ (online)

The online version of this paper was published 29 October 2002. URL: http://rjes.wdcb.ru/v04/tje02104/tje02104.htm in 2001 by a GIN RAS team headed by S. G. Skolotnev on board the R/V Akademik Ioffe. These studies have yielded further evidence for sulfides occurrences at the predicted locality, as well as in another low seismicity rift segment, the Markov Hole, which is the deepest (4975 m BSL) basin in the MAR rift zone.

The above is weighty evidence that aseismic areas (i.e., those lacking large events and continuous record of small events along the entire length of the ridge) of slow spreading mid-ocean ridges are most favorable for hydrothermal systems, and, hence, for sulfide mineralization to form in. These considerations afford a prediction of localities that hold the greatest potential for sulfide mineralization in the Atlantic Ocean as well.

Our prediction draws on satellite altimetry data [Sandwell and Smith, 1997; Smith and Sandwell, 1997], earthquake epicenter distribution [CNSS..., 1997], and a variety of geological data.

\section{Hydrothermal Fields and Sulfide Mineralization: Structural Setting in the Atlantic}

To date, several active and inactive hydrothermal fields and methane plumes have been detected in the Atlantic Ocean between $14^{\circ} \mathrm{N}$ and Iceland (Figure 1).

\section{Location of Hydrothermal Fields}

Analyzing the tectonic setting of active hydrothermal fields discerns two principal groups. Group one (Rainbow, Lucky Strike, Reykjanes, etc.) cluster at those segments of 


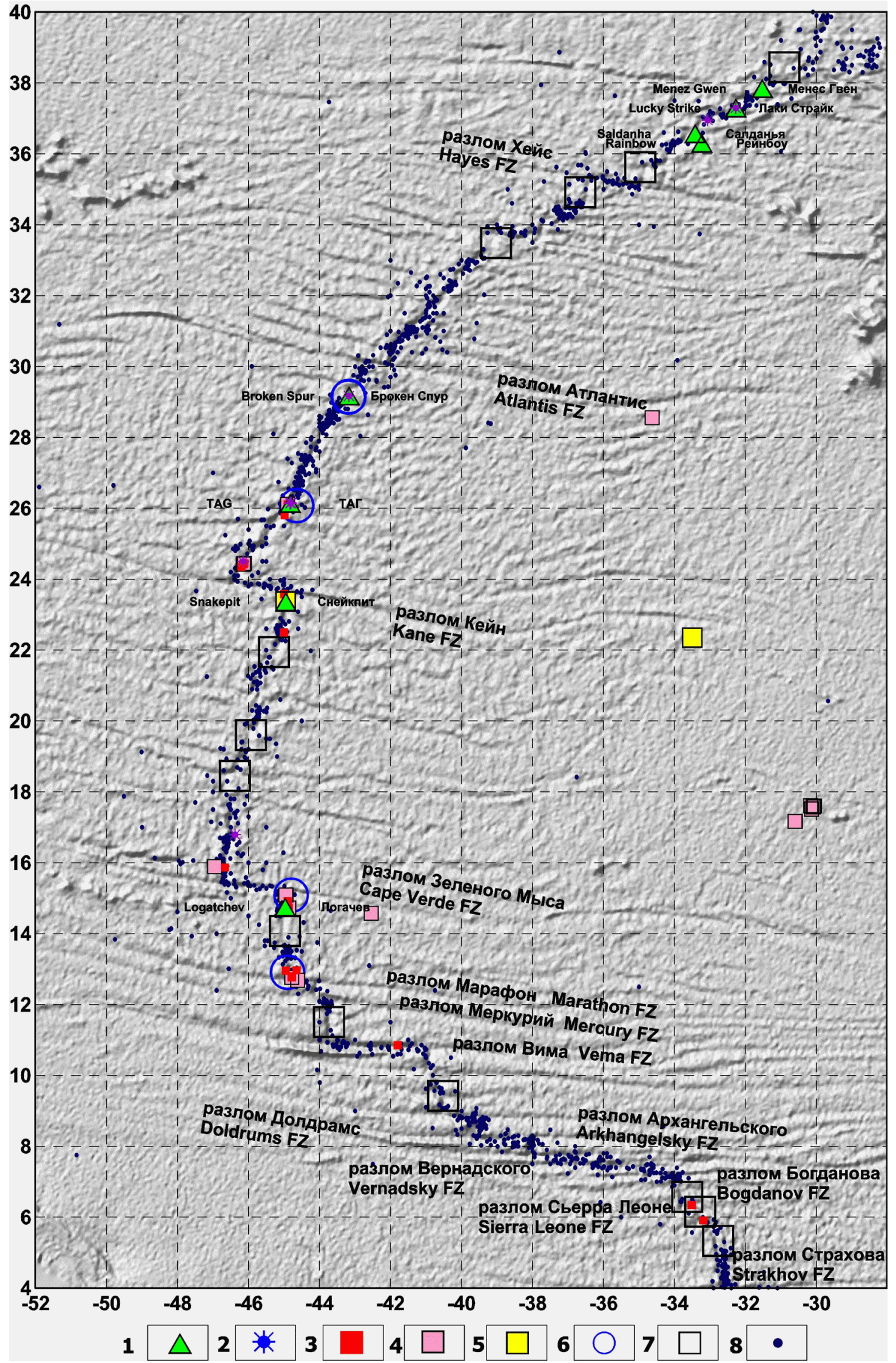


the Mid-Atlantic Ridge immediately adjacent to the Azores and Iceland hot spots. These portions of the spreading system are marked by the absence of fracture zones (FZ) with considerable offsets and by smooth topographic relief. Their structural characteristics have been repeatedly discussed in publications [e.g., Almukhamedov et al., 1990]. Group two (Broken Spur, TAG, etc.) are found in that segment of the ridge with major FZ (Atlantis, Kane, Cape Verde) hundreds of kilometers apart and with numerous discontinuities inbetween. Water depth above the fields ranges from hundreds of meters (as on the Reykjanes Ridge) to 3650 m (as on the TAG active mound). It is at the bends of rift valleys that black smokers cluster. This can be exemplified by the Broken Spur field (Figure 2A). Here, clearly visible are rift valley bends and fractures adjoining the valley.

The location of inactive hydrothermal fields coincides with zones of present-day hydrothermal activity, except for the edifices north of Cape Verde FZ and north of Kane FZ. In both cases, however, these are regions that are distinguished by relatively low seismicity. Water depth above the fields ranges from $1700 \mathrm{~m}$ (Lucky Strike) to $3900 \mathrm{~m}$ (at $24^{\circ} 30^{\prime} \mathrm{N}$ ).

\section{Setting of Sulfide Mineralization}

Sulfide mineralizations of various origins and bedrock zones showing strong hydrothermal imprints have a wider geographic spread, from the Atlantis FZ region to the Bouvet TJ. The stations that yielded sulfides lie in water depth between $2200 \mathrm{~m}$ (Fersman Smt.) and $4800 \mathrm{~m}$ (Markov Hole).

Alongside data of common knowledge, Russian and Western publications offer evidence contributing to the InterRidge database on sulfide mineralization and seafloor degassing. This information was acquired by the $\mathrm{R} / \mathrm{V}$ Antares (cruise 9, dredge 46; 1990), the R/V Akademik Nikolai Strakhov (cruise 7, dredge 71, 1988; cruise 9, dredges 27, 36, 41, 1989; cruise 18, dredge 43, 1994; cruise 22, dredge 34, 2000), the $\mathrm{R} / \mathrm{V}$ James Gillis (cruise 7309, dredges 58, 93, 1973), the R/V Pillsbury (cruise 7003, dredge 25, 1970), the $\mathrm{R} / \mathrm{V}$ Geolog Fersman (cruise not specified, dredges 74 , 130, 192), the R/V Akademik Ioffe (cruise 10, dredge 32, 2001), the R/V Gelenjik (cruise 96, dredge 17, 1996), and the R/V Akademik Kurchatov (cruise 20, the photograph of gas bubbles, 1975).

Sulfides were recovered from various parts of rift valley slopes, corner highs (Fersman Smt.), transverse ridges (on the west of the active segment of the Romanche FZ), directly from the FZ (Sierra Leone FZ) (Figure 3A), and outside present-day rifts (the Bouvet TJ region and Spiess
Ridge). Almost everywhere, sulfide occurrences were found to be associated with tectonization and strong hydrothermal imprints in wallrock and to coincide with low seismicity zones.

\section{Likely Structural Setting of Sulfide Mineralization in the South Atlantic Between the Equator and $55^{\circ} \mathrm{S}$}

In the South Atlantic, only sporadic sulfide occurrences and a unique indication of hydrothermally altered rocks (at $24^{\circ} \mathrm{S}$ ) have been reported (Figure 4). The Mid-Atlantic Ridge trends roughly NS without major bends or transform offsets. Overlaying earthquake epicenters on altimetry data shows that here, just as in the North Atlantic, aseismic segments exist, some of them being larger than those in the North Atlantic (south of Ascension I., 52 ${ }^{\circ} \mathrm{S}$ ) (Figure 4). Noteworthy is that they can be either related or unrelated to FZ. In view of the considerations discussed in the previous section, it is probably worthwhile to focus on the former. Promising areas like this could be found south of Ascension I. (which is remarkably complex in architecture), between the Martin Vaz and Hotspur FZ, $20^{\circ} \mathrm{S}$ (Figure 3B), and at $45^{\circ} \mathrm{S}$. Two similar localities exist on the Southwest Indian Ridge (Figure 4), in the Shaka FZ and Jabaru FZ regions.

Of special interest are aseismic zones in the Bouvet TJ region. As mentioned above, these zones have also yielded sulfide mineralization. One locality is the Spiess Ridge, on which a vast caldera has been mapped. The large Axial Volcano caldera, albeit occurring in a different geodynamic setting (on the Juan de Fuca Ridge), is known to be associated with a major hydrothermal field, currently being studied in the framework of the NeMO (New Millennium Observatory) Project (http://newport.pmel.noaa.gov/nemo_cruise98/ project.html). Another locality is situated directly near Bouvet I. in other words in the vicinity of the Bouvet TJ hot spot.

\section{Discussion}

Over a timespan of more than 100 years, the Mid-Atlantic Ridge has been dredged relatively thoroughly. We do not know the total number of samples obtained, yet the number of stations that we have data from is 4500. Judging from this random sample, the ridge has been studied in a depth range

Figure 1. Location of active and inactive hydrothermal fields and sulfide mineralization in the northern part of the Mid-Atlantic Ridge. Hereinafter, latitudes and longitudes are given in degrees (to the first decimal place). Topographic base, from satellite altimetry data [Smith and Sandwell, 1997]. Earthquake epicenters, from CNSS Earthquake Composite Catalog.

1-2 hydrothermal fields: 1 - active (with proper names) and 2 - inactive; 3 - sulfide mineralization; 4 - hydrothermal alteration; 5 - metalliferous sediments; 6 - methane plume; 7 - area with potential for sulfide mineralization and/or active hydrothermal fields; 8 - earthquake epicenter. 

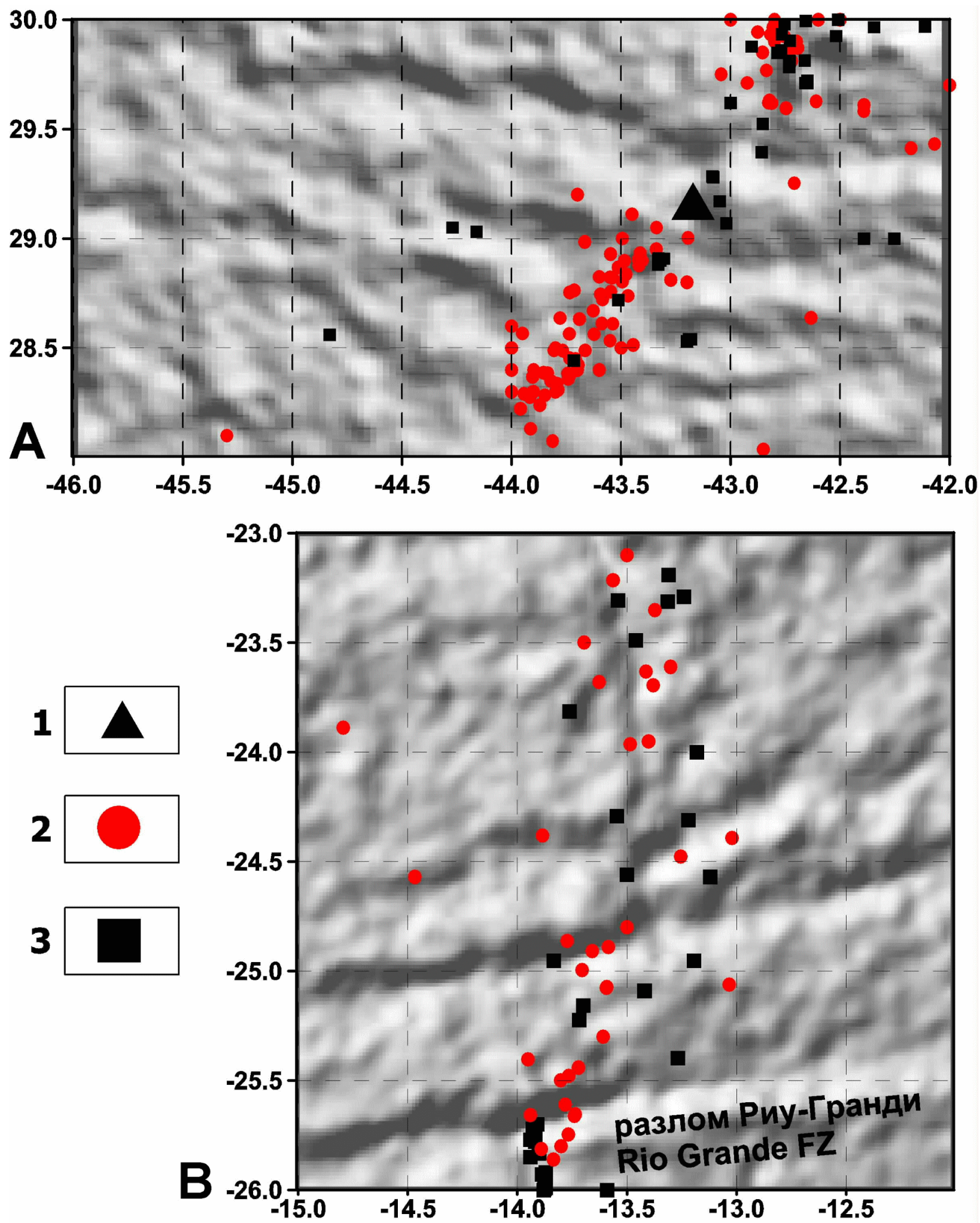

Figure 2. Relationship of discontinuities and aseismic segments of the Mid-Atlantic Ridge. A - location of the Broken Spur field. B - study area in the South Atlantic. Earthquake epicenters, from $[C N S S . .$. , 1997]. Cartographic base, from predicted topography [Smith and Sandwell, 1997].

1 - Broken Spur active hydrothermal field, 2 - earthquake epicenter, 3 - dredge station. 


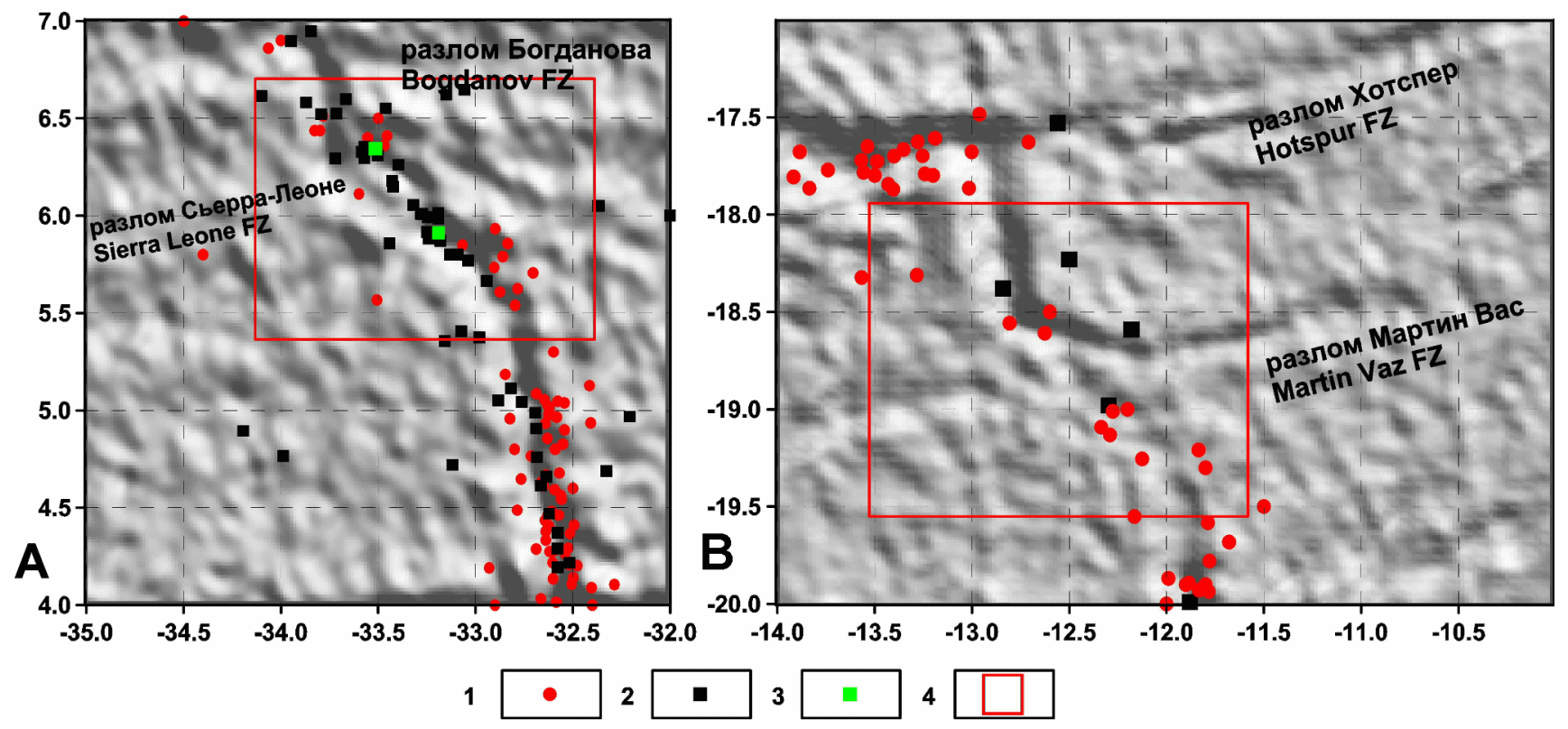

Figure 3. Location of sulfide mineralization with respect to aseismic segments of the Mid-Atlantic Ridge (Sierra Leone FZ region) (A) and a structurally similar portion of the South Atlantic (B). Earthquake epicenters, from [CNSS..., 1997]. Cartographic base, from predicted topography [Smith and Sandwell, 1997].

1 - earthquake epicenter, 2 - dredge station, 3 - dredge station with sulfide mineralization; 4 - structurally similar areas.

from $5000 \mathrm{~m}$ to a few tens of meters. Sampling involved all the principal structures of rift valleys and active segments of the FZ, with the percentage of dredge hauls with sulfide mineralization being very low. Thus, of the ca. 850 dredge hauls performed by the R/V Akademik Nikolai Strakhov, only six $(0.7 \%)$ brought sulfides. This implies that sulfides do not occur in a continuous belt along the entire length of the ridge, but are constrained to within certain nodes.

The nature of aseismic segments of the ridge appears to be critical to unraveling the setting of sulfide mineralization. Most likely, these segments are zones of relatively high heat flow, which is responsible for lithospheric ductility. This is further supported by heat flow data [Podgornykh and Khutorskoy, 1997]. It is aseismic zones of the MAR axial zone (as, e.g., in the Markov Hole region, at $10^{\circ} \mathrm{N}$, and at St. Peter FZ) that elevated heat flow values $\left(>70 \mathrm{~mW} / \mathrm{m}^{2}\right)$ have been recorded from. Elevated heat flow values, however, have been documented on transverse ridges (Vema FZ) as well. The anomalous nature of these regions is also expressed topographically. Here, rather complexly built nodes exist, whose distinctive feature is large blocks sitting inside fracture zones (e.g., Georgy Leonov Smt. in Sierra Leone FZ; St. Peter FZ; the rift segment between Cape Verde and Marathon FZ), and which were mapped reliably enough using multibeam echo sounders during the R/V Akademik Nikolai Strakhov cruises. Judging from the "predicted topography" data [Smith and Sandwell, 1997], such zones exist in the South Atlantic as well (Figures 3B, 4).

Let us now discuss the data correlation on a profile along the Mid-Atlantic Ridge (Figure 5). This plot shows gen- eralized information on (i) topographic relief and the free air gravity field, (ii) seismicity, (iii) distribution of sulfide mineralization, (iv) Bouguer anomalies, and (v) seismic tomography. With respect to everything pertaining to sulfide mineralization proper, seismic tomography, seismicity, and gravity anomalies provide a background data set, based on which correlation is performed. This data set enables an internally consistent interpretation of correlative anomalies and those features discernible on the profile. This is detailed below.

The seismic tomography pattern obtained from $\mathrm{S}$ wave data best reflects the temperature regime and partially molten state of the mantle [Becker and Boschi, 2002]. Our analysis draws on the RG5.5 model [Zhang and Tanimoto, 1992] for spherical harmonics up to the 36th order parametrized on $5^{\circ} \times 5^{\circ}$ blocks, in particular, a velocity variation profile along the MAR to a $500 \mathrm{~km}$ depth. This profile shows clearly three minima (Figure 5C), corresponding (from north to south) to the Iceland, Azores, and South Atlantic plumes. Above these plumes, basaltic magmatism is especially extensive [Dmitriev et al., 1999b]. In combination with slow spreading, this gives rise to conspicuous positive anomalies of seafloor topography along the ridge axis, because in these MAR zones basaltic products are accumulated appreciably more vigorously than in zones of "background type" magmatism [Dmitriev et al., 2001c]. These topographic anomalies induce free air gravity anomalies (Figure 5A), largely reflecting variations of the most contrasting density discontinuity, the water/seafloor (crust) boundary. In compliance with the classic $\left(2.75 \mathrm{~g} / \mathrm{cm}^{3}\right.$ den- 


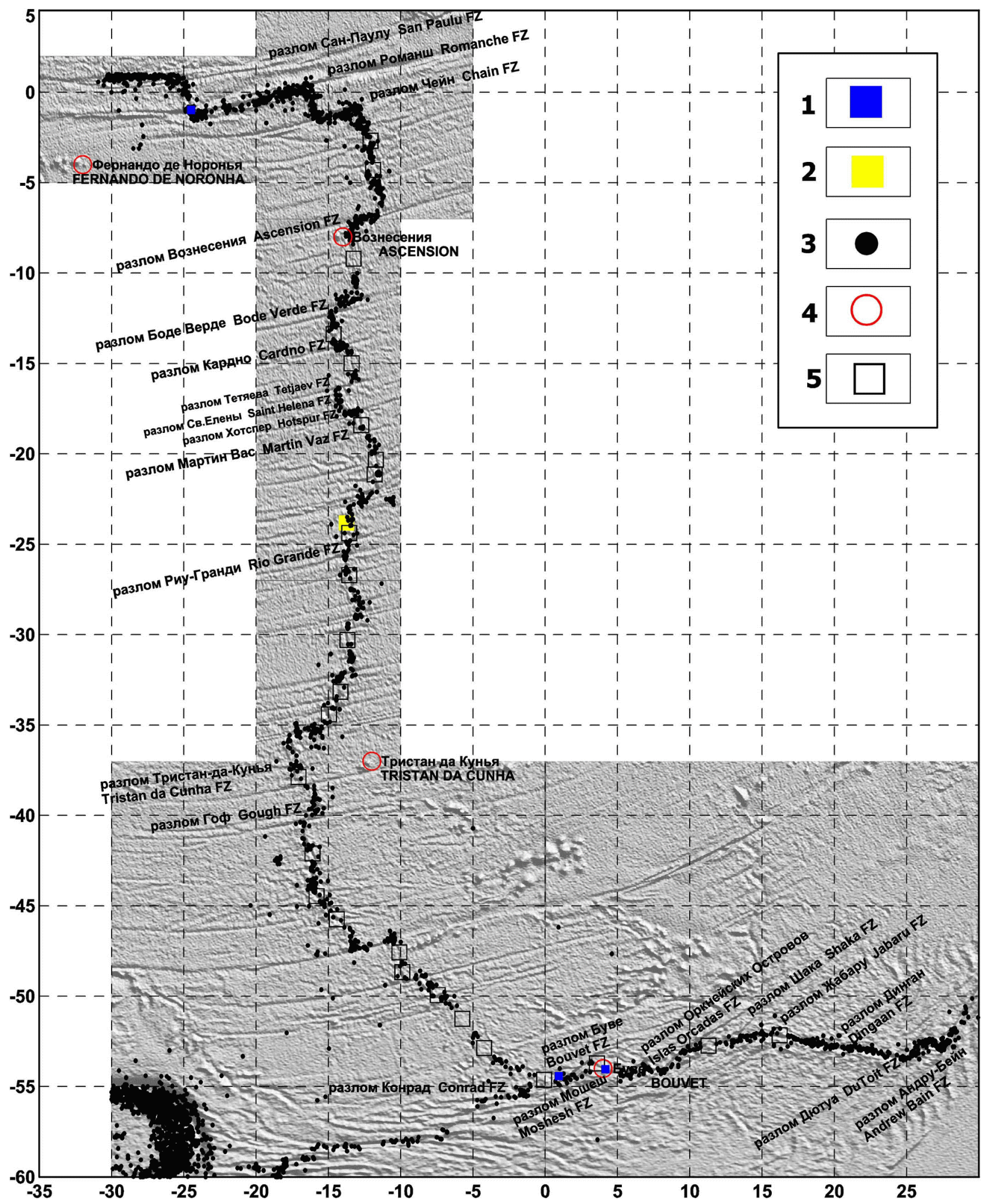

Figure 4. Map showing predicted sulfide occurrences in the southern part of the Mid-Atlantic Ridge. Topographic base, from satellite altimetry data [Sandwell and Smith, 1997]. Earthquake epicenters, from CNSS Earthquake Composite Catalog.

1 - sulfide mineralization, 2 - hydrothermal alteration, 3 - earthquake epicenter, 4 - hot spot, 5 - area with potential for sulfide mineralization and/or active hydrothermal fields. 


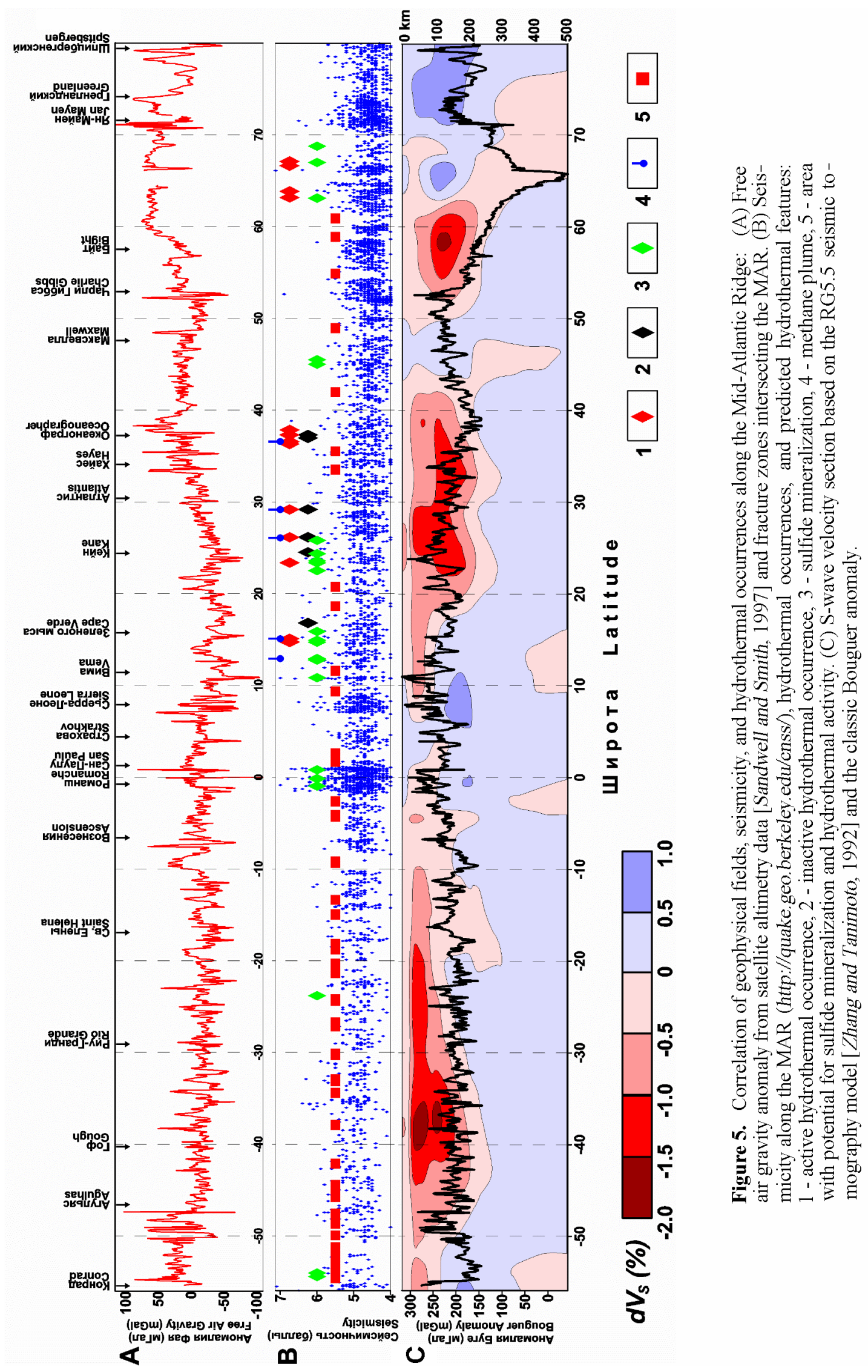


sity) Bouguer anomaly scheme, removing topographic influence from free air gravity anomalies leaves an anomalous field that is induced chiefly by variations of the Moho, because this is the next most contrasting nearsurface boundary in the density section (Figure 5C). The Bouguer anomaly thus obtained, due to isostatic mechanisms at work, is a mirror image (with respect to free air anomalies) of the topographic anomalies induced by extensive basaltic melts of the plume assemblage. In addition to the Moho influence, this anomaly includes correction for deeper seated (but less contrasting) density inhomogeneities, whose contributions to the anomalous field we have not separated. On the tomography section, note the match of the principal Bouguer lows and their correlative minima, represented by zones of low density mantle, as well as the marked (ca. 10 arc degrees, or $\sim 1000 \mathrm{~km}$ ) southward displacement of the Azores and Iceland plumes. Tomographic anomalies are displaced in this manner from Bouguer anomalies because the contribution from deep seated density variations is considerably smaller than that from the Moho. This implies that the region of low density mantle plume material is displaced from the relatively extensive basaltic melts, marked by gravity anomalies. The above is not at variance with the published data on the southward migration of the Azores plume [Cannat et al., 1999; Dmitriev et al., 2001b, 2001d].

Let us now analyze Figure 5B, which draws on seismic data [CNSS..., 1997]. On Figure 5, correlation of seismicity with the other geophysical parameters shows that in plume regions, seismic events are more frequent and have lower magnitudes than those in the "cool" mantle region near the equator and in certain fragments to the north. Correlation of seismicity to geophysical and petrologic parameters is detailed in [Dmitriev et al., 1999b]. The above does not apply to the reduced frequency of seismic events in the South Atlantic, which is an artifact of the sparser network of recording stations in this part of the world. It is readily apparent that along-ridge seismicity distribution shows "clusters" ca. 1.5-2 arc degrees across, with the documented sulfide occurrences and other related phenomena gravitating to spaces between the "clusters." In discussing the relatively well-understood North Atlantic, it is worth notice that sulfide occurrences gravitate not to zones of large, infrequent seismic events (considering samples of M $4+$ events) as such, but to zones associated with plume phenomena in the upper mantle.

In our opinion, the most likely underlying cause of this relationship is that the presence of a plume propagating (or simply functioning) along the ridge gives rise to an additional joint system in the crust, which facilitates water influx and circulation and water enrichment in components typical of hydrothermal solutions. In addition, extensive plumerelated basaltic magmatism, the supply of essential volatiles in the plume zone, and elevated heat flow, make for promoting hydrothermal activity. Fractured zones also promote serpentinization processes and associated methane generation [Charlou et al., 1998; Dmitriev et al., 1999a, 2001a]. It is also observed that active hydrothermal edifices are displaced slightly southward from inactive ones, which may be further evidence for migration of the plume and its related hydrothermal systems. This implies that products of hydrothermal activity, potentially taking place in zones lacking large seismic events, may be detected not only in the regions of present-day mantle plumes, but also in those areas outside the MAR zone that contain inactive hydrothermal edifices.

\section{Conclusions}

Let us summarize the regularities of sulfide distribution along the MAR.

(1) In the MAR axial zone, active and inactive hydrothermal edifices and sulfide mineralization are not distributed randomly, but are confined to zones of elevated ductility, marked by low seismicity (for samples of $4+\mathrm{M}$ events).

(2) In association with these zones, one often finds discontinuities that may offer further evidence for the low density (elevated ductility) of the crust in these portions of the MAR.

(3) In searching for hydrothermal edifices and sulfide mineralization, it is worthwhile to focus, in addition to the above, on plume zones, as detected from seismic tomography data in both the North and South Atlantic.

\section{References}

Almukhamedov, A. I., Yu. A. Bogdanov, M. I. Kuzmin, et al., The Rift Zone of the Reykjanes Ridge: Tectonics, Magmatism, and Depositional Conditions, 236 pp., Nauka, Moscow, 1990.

Becker, T. W., and L. Boschi, A comparison of tomographic and geodynamic mantle models, in Geochemistry, Geophysics, Geosystems, G3, 3, January 10, 2002, Paper no. 2001GC000168. Bonatti, E., B. M. Guerstein-Honnorez, J. Honnorez, and G. Stern, Hydrothermal pyrite concretions from the Romanche trench (Equatorial Atlantic): metallogenesis in oceanic fracture zones, Earth Planet. Sci. Lett., 32, (1), 21-37, 1976.

Cannat, M., A. Briais, C. Deplus, et al., Mid-Atlantic RidgeAzores hotspot interactions: along-axis migration of a hotspotderived event of enhanced magmatism 10 to 4 Ma ago, Earth Planet. Sci. Lett., 173, 257-269, 1999.

Carrara, G., G. Bortoluzzi, N. Zitellini, E. Bonatti, et al., The Bouvet triple junction region (South Atlantic): A report on two geological expeditions, Giornale di Geologia, Ser. 3a, (59/1-2), 19-33, 1997.

Charlou, J. L., Y. Fouquet, H. Bougault, et al., Intense $\mathrm{CH}_{4}$ plumes generated by serpentinization of ultramafic rocks at the intersection of the $15^{\circ} 20^{\prime} \mathrm{N}$ fracture zone and the Mid-Atlantic Ridge, Geochim. Cosmochim. Acta, 62, (13), 2323-2333, 1998. CNSS Earthquake Composite Catalog, June 1997

(http://quake.geo.berkeley.edu/cnss/).

Dmitriev, L., B. Bazylev, S. Silantiev, M. Borisov, S. Sokolov, and H. Bougault, Formation of hydrogen and methane during serpentinization of mantle peridotites: Implications for petroleum genesis (in Russian), Russ. J. Earth Sci., 1, (6), 1999a.

Dmitriev, L., S. Sokolov, W. G. Melson, and T. O'Hirn, Plume and spreading basaltic associations and their reflection in petrological and geophysical parameters of Mid Atlantic Ridge northern part (in Russian), Russ. J. Earth Sci., 1, (6), 1999b.

Dmitriev, L. V., B. A. Bazylev, M. V. Borisov, H. Bougault, S. A. Silantiev, and S. Yu. Sokolov, The serpentinization of the oceanic mantle peridotites and the Earth fluid regime, European Geophysical Society, 26th General Assembly, Geoph. Res. Abs., 3, 795, 2001a.

Dmitriev, L. V., N. V. Koronovsky, S. Yu. Sokolov, and N. S. Sokolov, Tectonic-magmatic history of the North Atlantic lithosphere formation by the isochron gravity profiling, 
European Geophysical Society, 26th General Assembly, Geoph. Res. Abs., 3, 818, 2001b.

Dmitriev, L. V., S. A. Silantiev, and S. Yu. Sokolov, Plume and spreading TOR assemblages, spreading rate, ridge segmentation and geophysical fields distribution, European Geophysical Society, 26th General Assembly, Geoph. Res. Abs., 3, 819, 2001c.

Dmitriev, L. V., S. Yu. Sokolov, N. V. Koronovsky, and N. S. Sokolov, Migration of the Azores superplume: Evidence from correlation of petrologic and geophysical parameters, in Geology and Geophysics of Mid-Ocean Ridges. InterRidge, Russian Division, 11, May 23-25, 2001d.

Dubinin, E. P., and S. A. Ushakov, Oceanic Rifting, 293 pp., GEOS, Moscow, 2001.

Hannington, M., Hydrothermal Vent Database, InterRidge Databases, 2001 (http://triton.ori.u-tokyo.ac.jp/ intridge/data1.html).

Lukashin, V., A. Lisitsyn, G. Ivanov, V. Kravtsov, and V. Rusakov, A study of hydrothermal plumes above the rift zone of the Mid-Atlantic Ridge at $29^{\circ} \mathrm{N}$ (in Russian), Okeanologiya, 37, (5), 770-779, 1997.

Mazarovich, A. O., Geology of the Central Atlantic: Fractures, Volcanic Edifices, and Oceanic Bottom Deformations, 176 pp., Nauchy Mir, Moscow, 2000.

Mazarovich, A., and S. Sokolov, Tectonic position of the hydrothermal fields of the Mid-Atlantic Ridge (in Russian), Litol. Polezn. Iskop., 4, 436-439, 1998.

Mazarovich, A., V. Simonov, A. Peyve, et al., Hydrothermal mineralization in Sierra Leone Fracture Zone (Central Atlantic) (in Russian), Litol. Polezn. Iskop., 5, 1-8, 2001.

Report on the R/V Akademik Kurchatov Cruise 20 (A Geologic and Geophysical Expedition in the Atlantic Ocean, Jan. 29 to May 29, 1975, Inst. Oceanol., USSR Acad. Sci., 1975.
Peyve, A., E. Bonatti, D. Brunelli, et al., New data on some major MAR structures: preliminary results of R/V Akademik Nikolaj Strakhov 22 cruise, InterRidge News, 9, (2), 28, 2000.

Podgornykh, L. V., and M. D. Khutorskoy, Map of the planetary heat flow, scale 1:30 000 000, VNIIOkeangeologiya, MoscowSt. Petersburg, 1997.

Pogrebitsky, Yu., Yu. Goryachev, V. Osipov, and A. Trukhalev, Structure of the oceanic lithosphere: Evidence from the AngolaBrazil geotraverse (in Russian), Sov. Geol., 12, 8-22, 1990.

Raznitsyn, Yu., S. Skolotnev, N. Turko, A. Mazarovich, A. Peyve, and L. Shterenberg, The junction zone of the Marathon FZ and rift valley: Structure, lithology, and sulfide mineralization (Central Atlantic) (in Russian), Dokl. Akad. Nauk SSSR, 320, (4), 952-956, 1991.

Sandwell, D. T., and W. H. F. Smith, Marine Gravity Anomaly from Geosat and ERS-1 Satellite Altimetry, J. Geophys. Res., 102, (B5), 10,039-10,054, 1997.

Sharapov, V. V., and V. A. Simonov (Eds.), Geologic Studies in the Central Atlantic, 192 pp., IGiG SOAN SSSR, Novosibirsk, 1991

Smith, W. H. F., and D. T. Sandwell, Global seafloor topography from satellite altimetry and ship depth soundings, Science, 277, (5334), Sept. 26, 1997.

Trukhalev, A. I., P. V. Vorob'ev, T. V. Stepanova, and M. A. Stepanov, Some tectonic and magmatic characteristics of the Mid-Atlantic Ridge rift zone at $24^{\circ} \mathrm{N}$ and $25^{\circ} \mathrm{N}$, in Hydrothermal Systems and Sedimentary Assemblages of Midocean Ridges of the Atlantic, pp. 72-112, Nauka, Moscow, 1993. Zhang, Y. S., and T. Tanimoto, Ridges, hotspots and their interaction, as observed in seismic velocity maps, Nature, 355, 45-49, 1992.

(Received 17 October 2002) 